\title{
COVAR: Computer Program for Multifactor Relative Risks and Tests of Hypotheses Using a Variance-Covariance Matrix from Linear and Log-Linear Regression
}

\author{
Leif E. Peterson \\ Center for Cancer Control Research \\ Baylor College of Medicine \\ Houston, Texas 77030
}

November 3, 1997

\begin{abstract}
A computer program for multifactor relative risks, confidence limits, and tests of hypotheses using regression coefficients and a variance-covariance matrix obtained from a previous additive or multiplicative regression analysis is described in detail. Data used by the program can be stored and input from an external disk-file or entered via the keyboard. The output contains a list of the input data, point estimates of single or joint effects, confidence intervals and tests of hypotheses based on a minimum modified chi-square statistic. Availability of the program is also discussed.
\end{abstract}

Key Words: Relative Risks, Confidence Limits, Matrix Manipulation, Hypothesis Testing

\section{INTRODUCTION}

Additive and multiplicative models are widely used in epidemiology to obtain maximum likelihood (ML) estimates of relative risks (RR), odds-ratios (OR) and hazard ratios (HR). Numerous computer programs have been developed that generate ML estimates of regression coefficients and variance-covariance matrices [1, 2, 3, 4, 5]. Despite this wide diversity of programs, there is a shortage of stand alone algorithms that allow the statistician to generate multifactor relative risks and confidence limits, and conduct tests of hypotheses using results of previous regression analyses.

This report documents a computer program to obtain point estimates and confidence intervals (CI) of RR for single or joint effects using the regression coefficients and a variance-covariance matrix from a previous modeling session.

The program has been developed mainly for Grizzle-Starmer-Koch (GSK) regression models for multinomial categorical data, Cox proportional hazards ( $\mathrm{PH})$, logistic and Poisson regression results, but can be used with the results of other models. The critical data required to apply the computer code are:

- Number of parameters

- Variable names and regression coefficients

- Variance-covariance matrix

- Probability (1- $\alpha$ ) of the confidence interval of RR

- Number of coefficients used in RR or tests of hypotheses

- Units applied to each coefficient in RR estimation

There is only one output format, listing the regression coefficients, their names, variance-covariance matrix, point estimates, corresponding CIs, minimum modified $\chi^{2}$ tests of hypotheses with one-sided tail probabilities and units applied to each coefficient. The program and all of its subroutines are written in FORTRAN-77 and are run on a desktop PC with an AMD-K6-166MHz chip. The algorithm may be compiled and run on Unix machines as 
well. The PC version of the executable requires about 176,000 bytes of random access memory (RAM) to operate. Average execution time is about 1 second per run.

\section{PROGRAM DESCRIPTION}

The computer program proceeds as follows. The method of entering parameter names, regression coefficients, and the variance-covariance matrix is specified by the user. The choices are to enter the data from the keyboard or from an external disk-file. If the keyboard is selected as the means of entering data, the user is queried for all of the necessary data. When using the disk-file for data entry, the number of parameters, $p$, is first read in, followed by the $p$ variable names and $p$ regression coefficients. This is followed by entry of $\left(\left(p^{2}-p\right) / 2\right)+p$ elements of the variance-covariance matrix. One should note that, since the variance-covariance matrix is symmetric, only the lower triangular is required.

Once the number of parameters, variable names, coefficients and variance-covariance matrix are entered via the keyboard or disk-file, the user must enter the number of coefficients used in RR or tests of hypotheses to be considered for this run. For each coefficient used in RR estimation, i.e., variable, the user must specify the variable index and the units to be considered. Next, the user must specify for each factor one of the following three options: (1) estimate RR and CI, (2) use contrast matrix for test of hypothesis about $\mathbf{b}=\mathbf{0}$, or (3) use a contrast matrix to test for a trend in $\mathbf{b}=\mathbf{0}$. If $\mathrm{RR}$ and $\mathrm{CI}$ is specified, the program queries the user for the probability to be used for estimating the CI of RR. The choices are $80 \%, 90 \%, 95 \%, 97.5 \%$ and $99 \%$, with the last choice left as an option to enter a probability that is different from those listed above.

\section{$2.1 \quad$ NOTATION AND THEORY}

Thus far we have discussed the program's necessary input data. In this section we will address the relationship between asymptotic likelihood theory and the ML estimation of the regression coefficients and variance-covariance matrix. According to asymptotic likelihood theory, the score vectors of a regression model are

$$
U(\mathbf{b})=\frac{\partial \log L(\mathbf{b})}{\partial \mathbf{b}},
$$

where $\log L$ is the $\log$ of the likelihood function for the particular model under consideration, that is, the GSK, Cox proportional hazards, logit, Poisson or other model. The Fisher information matrix $I(b)$ of the score vectors is

$$
\begin{aligned}
\mathbf{I}(b) & =E\left[U(\mathbf{b}) U^{T}(\mathbf{b})\right] \\
& =-\left[E\left(\frac{\partial^{2} \log L(\mathbf{b})}{\partial \mathbf{b}_{\mathbf{j}} \partial \mathbf{b}_{\mathbf{k}}}\right)\right],
\end{aligned}
$$

the generalized-inverse of which is the variance-covariance matrix, $V_{b}$, written as

$$
\mathbf{V}_{\mathbf{b}}=\left(\begin{array}{cccc}
\sigma^{2}\left(b_{0}\right) & \sigma\left(b_{0}, b_{1}\right) & \cdots & \sigma\left(b_{0}, b_{j}\right) \\
\sigma\left(b_{0}, b_{1}\right) & \sigma^{2}\left(b_{1}\right) & \cdots & \sigma\left(b_{1}, b_{j}\right) \\
\vdots & \vdots & \ddots & \vdots \\
\sigma^{2}\left(b_{0}, b_{j}\right) & \sigma\left(b_{1}, b_{j}\right) & \cdots & \sigma^{2}\left(b_{j}\right)
\end{array}\right)
$$

which is a $p \times p$ real symmetric matrix whose principal diagonal consists of the parameter variances. The offdiagonals are the covariances between each of the coefficients. Most computer programs print the diagonal and the upper or lower triangular of the variance-covariance matrix, which makes no difference since the matrix is symmetric. When Newton-Raphson iteration is used for convergence, $\mathbf{V}_{b}$ is the generalized-inverse of the Fisher information matrix. For iteratively reweighted least squares (IRLS) regression, $\mathbf{V}_{b}$ is the generalized-inverse of the weighted dispersion matrix shown as

$$
\begin{aligned}
\mathbf{V}_{\mathbf{b}} & =\mathbf{I}(\mathbf{b}) \\
& =\left(\mathbf{X}^{\mathrm{T}} \mathbf{V X}\right)^{-1}
\end{aligned}
$$


A best-asymptotic-normal (BAN) estimate of the parameter vector $\mathbf{b}$ is obtained by adding the solution vector

$$
\Delta \mathbf{b}=\left(\mathbf{X}^{\mathrm{T}} \mathbf{V X}\right)^{-1} \mathbf{X}^{\mathrm{T}} \mathbf{V} \mathbf{Y}
$$

to the previous parameter vector at each iteration

$$
\mathbf{b}_{(i+1)}=\mathbf{b}_{i}+\Delta \mathbf{b}_{(i+1)}
$$

which results in $\mathbf{b}$ at convergence

$$
\mathbf{b}=\left(\begin{array}{c}
b_{0} \\
b_{1} \\
b_{2} \\
\vdots \\
b_{p}
\end{array}\right)
$$

In (5) $\mathbf{X}$ is the design matrix, $\mathbf{W}$ is a diagonal matrix of inverse variance weights and $\mathbf{Y}$ is the column vector of residuals. Using $\mathbf{b}$ and $\mathbf{V}_{\mathbf{b}}$ from, for example, a four-variable model including terms for an intercept $b_{0}$ and three risk factors $\left(b_{1}, b_{2}\right.$, and $\left.b_{3}\right)$, the point estimate of $R R$ for the three factors considered jointly is

$$
R R=\exp \left(b_{1} u_{1}+b_{2} u_{2}+b_{3} u_{3}\right)
$$

where $b_{1}, b_{2}$, and $b_{3}$ are the regression coefficients and $u_{1}, u_{2}$ and $u_{3}$ are the units applied to the coefficients. The $R R$ in (8) is based on reference cell coding where each $p$-level risk factor is coded with $p-1$ independent variables. The Taylor series-based $(1-\alpha)$ cofidence interval (CI) for the interval estimate can be expressed by

$$
(1-\alpha) \mathrm{CI} R R=\exp \left(\ln (R R) \pm Z_{\alpha} \times \sqrt{V}\right) .
$$

Abramowitz and Stegun [6] give a useful method for determining percentage points of the standard deviate, $Z_{\alpha}$, in (9) for a specified a level in the form

$$
Z_{\alpha}=t-\left[\frac{c_{0}+c_{1} t+c_{2} t^{2}}{1+d_{1}+d_{2} t^{2}+d_{3} t^{3}}\right]
$$

where

$$
t=\sqrt{\ln \left(\frac{1}{\alpha^{2}}\right)}
$$

and

$$
\begin{array}{ll}
c_{0}=2.515517 & d_{1}=1.432788 \\
c_{1}=0.802853 & d_{2}=0.189269 \\
c_{2}=0.010328 & d_{3}=0.001308 .
\end{array}
$$

The variance, $V$, of the logarithm of the $R R(9)$ takes on the form

$$
V=\sum_{i}^{p} \sigma^{2}\left(b_{i}\right)\left(u_{i}^{*}-u_{i}\right)^{2}+\sum_{j}^{p} \sum_{i \neq j}^{p} \sigma_{i j}\left(b_{i}, b_{j}\right)\left(u_{i}^{*}-u_{i}\right)\left(u_{j}^{*}-u_{j}\right),
$$

where $\sigma^{2}\left(b_{i}\right)$ is the variance of $b_{i}, \sigma_{i j}\left(b_{i}, b_{j}\right)$ is the covariance between $b_{i}$ and $b_{j}(3)$ and $\left(u_{i}^{*}-u_{i}\right)$ and $\left(u_{j}^{*}-u_{j}\right)$ are the change in units applied to the coefficients. A test of hypothesis of no significant effect due to the joint factors of the parameters in $(8)$ is

$$
\mathrm{H}_{o}: b_{1}=b_{2}=b_{3}=0 \text {, }
$$

which can be rewritten as

$$
\mathrm{H}_{o}: \mathbf{C b}=\mathbf{0} \text {, }
$$

where $\mathbf{C}$ is the contrast matrix forming the desired linear combination of the regression coefficients for the threeparameter test. Thus, for the three joint factors in (8), the $\mathbf{C}$ matrix is

$$
\mathbf{C}=\left(\begin{array}{llll}
0 & 1 & 0 & 0 \\
0 & 0 & 1 & 0 \\
0 & 0 & 0 & 1
\end{array}\right)
$$


Grizzle, Starmer, and Koch [7] introduced the test statistic of the linear hypothesis $\mathrm{H}_{\mathbf{o}}: \mathbf{C b}=\mathbf{0}$, given by

$$
\chi^{2}=\mathbf{S S}(\mathbf{C b}=\mathbf{0})=\mathbf{b}^{\mathrm{T}} \mathbf{C}^{\mathrm{T}}\left[\mathrm{CV}_{\mathbf{b}} \mathbf{C}^{\mathrm{T}}\right]^{-1} \mathbf{C b},
$$

which is $\chi^{2}$ distributed with degrees of freedom equal to the number of independent rows in C. Matrix multiplication in (16) is first carried out by obtaining the outer products $\mathbf{b}^{T} \mathbf{C}^{T}$ and $\mathbf{C b}$. The variance-covariance matrix $\mathbf{V}_{b}$ is premultiplied by $\mathbf{C}$ to give $\mathbf{C V}_{b}$, which is postmultiplied by the transpose of $\mathbf{C}\left(\mathbf{C}^{T}\right)$ to give $\mathbf{C V}_{b} \mathbf{C}^{T}$. The inverse of $\mathbf{C V}_{b} \mathbf{C}^{T}$, that is, $\left[\mathbf{C V}_{b} \mathbf{C}^{T}\right]^{-1}$, is obtained by using singular value decomposition, which avoids such problems as nullity (zero elements), singularity and collinearity, which may be inherent in ill-conditioned or "sparse" matrices. Lastly, $\left[\mathbf{C V}_{b} \mathbf{C}^{T}\right]^{-1}$ is premultiplied by $\mathbf{b}^{T} \mathbf{C}^{T}$ then postmultiplied by $\mathbf{C b}$ to arrive at $\mathbf{b}^{T} \mathbf{C}^{T}\left[\mathbf{C V}_{b} \mathbf{C}^{T}\right]^{-1} \mathbf{C b}$. If the test statistic exceeds some tabled value of $\chi_{(d . f ., 1-\alpha)}^{2}$, then we conclude that there is a statistically significant joint effect in the presence of the three factors in our example.

\section{$2.2 \quad$ STRUCTURE}

CALL VAR(N,A,B,CON,M,U,X,Z,ITRND,BEGTRND,ENDTRND, ORDTRND,ITRD,ITER,IFLT,PLUS,RR,LL,UL,CHI2,PROB) 


\begin{tabular}{|c|c|c|c|}
\hline NP & Parameter & Work: & Maximum number of parameters \\
\hline NTITER & Parameter & Work: & $\begin{array}{l}\text { Maximum number of cycles (runs } \\
\text { per session) }\end{array}$ \\
\hline INFILE & Character & Input: & Input filename (optional) \\
\hline OUTFILE & Character & Input: & Output filename \\
\hline NCOL & Integer & Input: & Number of parameters \\
\hline $\mathrm{B}(\mathrm{NCOL})$ & Real & Input: & Column vector of coefficients, $\mathbf{b}$ \\
\hline $\mathrm{SE}(\mathrm{NCOL})$ & Real & Input: & Standard error of coefficients \\
\hline $\mathrm{X}(\mathrm{NCOL}, \mathrm{NCOL})$ & Real & Input: & Variance-covariance matrix, $\mathbf{V}_{b}$ \\
\hline $\mathrm{Z}$ & Real & Input: & Standard normal deviate \\
\hline NEFF & Integer & Input: & $\begin{array}{l}\text { Number of coefficients used in } \mathrm{RR} \\
\text { or tests of hypotheses }\end{array}$ \\
\hline AUNIT(NCOL) & Real & Input: & Units applied to coefficients \\
\hline BEGTRND(NCOL) & Integer & Input: & First coefficient in trend test \\
\hline ENDTRND(NCOL) & Integer & Input: & Last coefficient in trend test \\
\hline IRTEST(NTITER) & Integer & Input: & $\begin{array}{l}\text { Type of test for each row of } \mathbf{C} \text { ma- } \\
\text { trix }\end{array}$ \\
\hline ITEST(NCOL) & Integer & Input: & $\begin{array}{l}\text { Dummy variable for test of trend } \\
\text { during each cycle (run per session) }\end{array}$ \\
\hline ITER & Integer & Work: & Cycle, or number of tests performed \\
\hline $\mathrm{B} 1(\mathrm{NCOL}, 1)$ & Real & Work: & Column vector of coefficients, $\mathbf{b}$ \\
\hline $\mathrm{BT}(1, \mathrm{NCOL})$ & Real & Work: & Transpose of $\mathbf{b}$ vector \\
\hline $\mathrm{C}(\mathrm{NCOL}, \mathrm{NCOL})$ & Real & Work: & Contrast matrix $\mathbf{C}$ \\
\hline $\mathrm{CON}(\mathrm{NCOL}, \mathrm{NCOL}, \mathrm{NTITER})$ & Real & Work: & $\begin{array}{l}\text { Contrast matrix written at each cy- } \\
\text { cle }\end{array}$ \\
\hline $\mathrm{CB}(\mathrm{NCOL}, 1)$ & Real & Work: & $\begin{array}{l}\text { Cross-product of } \mathbf{C} \text { matrix and } \mathbf{b} \\
\text { vector, } \mathbf{C b}\end{array}$ \\
\hline $\mathrm{CT}(\mathrm{NCOl}, \mathrm{NCOL})$ & Real & Work: & Transpose of $\mathbf{C}$ matrix, $\mathbf{C}^{T}$ \\
\hline $\mathrm{CX}(\mathrm{NCOl}, \mathrm{NCOL})$ & Real & Work: & $\begin{array}{l}\text { Cross-product of } \mathbf{C} \text { and } \mathbf{V}_{b} \text { matri- } \\
\text { ces, } \mathbf{C V}_{b}\end{array}$ \\
\hline $\mathrm{CXC}(\mathrm{NCOl}, \mathrm{NCOL})$ & Real & Work: & $\begin{array}{l}\text { Cross-product of } \mathbf{C V}_{b} \text { and } \mathbf{C}^{T} \text { ma- } \\
\text { trices, } \mathbf{C V}_{b} \mathbf{C}^{T}\end{array}$ \\
\hline $\mathrm{CXC1}(\mathrm{NCOL}, \mathrm{NCOL})$ & Real & Work: & $\begin{array}{l}\text { Generalized inverse of } \mathbf{C V}^{b} \mathbf{C}^{T} \text { ma- } \\
\text { trix, }\left[\mathbf{C V}_{b} \mathbf{C}^{T}\right]^{-1}\end{array}$ \\
\hline $\mathrm{M} 1(1, \mathrm{NCOL})$ & Real & Work: & $\begin{array}{l}\text { Cross-product of } \quad \begin{array}{r}\mathbf{b}^{T} \mathbf{C}^{T} \\
\text { and }\left[\mathbf{C V}_{b} \mathbf{C}^{T}\right]^{-1} \\
\mathbf{b}^{T} \mathbf{C}^{T}\left[\mathbf{C V}_{b} \mathbf{C}^{T}\right]^{-1}\end{array} \text { matrices, }\end{array}$ \\
\hline $\operatorname{NUM}(1,1)$ & Real & Work: & $\begin{array}{l}\text { Cross-product of } \mathbf{b}^{T} \mathbf{C}^{T}\left[\mathbf{C V}_{b} \mathbf{C}^{T}\right]^{-1} \\
\text { and } \mathbf{C}_{b} \\
\mathbf{b}^{T} \mathbf{C}^{T}\left[\mathbf{C V}_{b} \mathbf{C}^{T}\right]^{-1} \mathbf{C b}\end{array}$ \\
\hline PIND(NCOL) & Integer & Work: & $\begin{array}{l}\text { Column vector used to set each row } \\
\text { of contrast matrix, } \mathbf{C}\end{array}$ \\
\hline $\mathrm{V}$ & Real & Work: & Variance of $\ln (R R)$ \\
\hline
\end{tabular}




\begin{tabular}{|c|c|c|c|}
\hline SD & Real & Work: & Square-root of $\mathbf{V}$ \\
\hline $\mathrm{BU}$ & Real & Work: & $\begin{array}{l}\text { Sum-product of coefficients and } \\
\text { units } \sum b_{i} U N I T_{i}\end{array}$ \\
\hline PLUS(NCOL) & Character & Output: & $\begin{array}{l}\text { Column vector of ' }+ \text { ' and '-' sym- } \\
\text { bols, with '+' representing the spec- } \\
\text { ified factors }\end{array}$ \\
\hline $\mathrm{RR}$ & Real & Output: & Relative risk \\
\hline LL & Real & Output: & Lower bound of relative risk \\
\hline $\mathrm{UL}$ & Real & Output: & Upper bound of relative risk \\
\hline $\mathrm{CHI} 2$ & Real & Output: & Chi-square test statistic \\
\hline PROB & Real & Output: & One-sided tail probability \\
\hline IFLT & Integer & Output: & $\begin{array}{l}\text { Premature exit code } \\
0=\mathrm{OK} \\
1=(Z=0) \\
2=(N E F F=0) \\
3=\left(b_{i}=0\right) \\
4=\left(U N I T_{i}=0\right) \\
5=\left(I N D_{i}=0\right) \\
6=(V=0)\end{array}$ \\
\hline
\end{tabular}

\subsection{AUXILIARY ALGORITHMS}

The algorithms MATMUL, TRNPOS, MATINV, SVDCMP are required. MATMUL is used for matrix multiplication; TRNPOS is used to tranpose matrices, both given in [8]. MATINV performs a check on the singular values returned from the singular value decomposition algorithm $S V D C M P$ based on [9]; the function $C U M N O R$ returns $Z_{\alpha}$ for a given $\alpha$; the functions $A L G$ and GAMAIN return the $\chi^{2}$ tail probabilities for a given $\chi^{2}$ value and d.f.

\subsection{RESTRICTION}

All input parameters are checked for nullity and a fault message is returned if there is an illegal entry.

\subsection{TIME}

A thorough investigation of absolute timing has not been performed; however, it should be noted that execution time is a function of the number of model parameters and factors to be considered.

\subsection{PRECISION}

The algorithm may be converted to double precision by making the following changes:

1. Change REAL to DOUBLE PRECISION in the algorithm.

2. Change the constants to double precision.

3. Change EXP to $D E X P$ and $A L O G$ to $D L O G$ in all applicable routines.

4. Make appropriate changes in auxiliary routines MATMUL, TRNPOS, MATINV, SVDCMP, and in functions $A L G$ and $G A M A I N$. 


\subsection{APPLICATION}

\subsubsection{Estimating Relative Risk for Multiple Risk Factors}

Let us take, as an example, the results of a unconditional (unmatched) logistic regression analysis of oral contraceptive use (OC), smoking and myocardial infarction (MI) found in [10]. The coefficients are given as

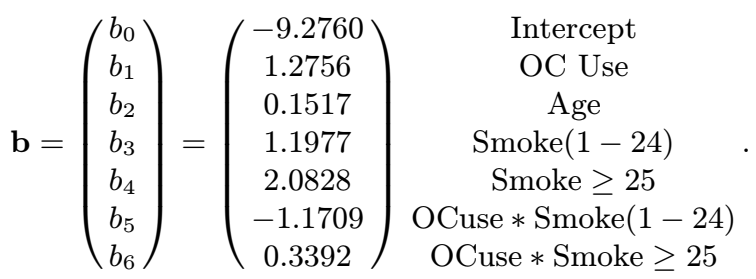

where the variable names to the right of the coefficients are the intercept, OC use (coded 0-no, 1-yes), age (continuous variable), smoking 1-24 cigarettes per day (coded 0-no, 1-yes), smoking $\geq 25$ cigarettes per day (coded 0-no, 1-yes), interaction term for OC use and smoking 1-24 cigarettes per day and an interaction term for OC use and smoking $\geq 25$ cigarettes per day. The variance-covariance matrix $\mathbf{V}_{b}$ for our example is

$$
\mathbf{C}=\left(\begin{array}{ccccccc}
0.4045 & \cdot & \cdot & \cdot & \cdot & \cdot & \cdot \\
-0.0676 & 0.3345 & . & . & \cdot & \cdot & \cdot \\
-0.0087 & 0.0008 & 0.0002 & . & . & \cdot & \cdot \\
-0.0387 & 0.0324 & 0.0002 & 0.0476 & . & . & \cdot \\
-0.0470 & 0.0332 & 0.0004 & 0.0321 & 0.0489 & . & \cdot \\
0.0140 & -0.3294 & 0.0004 & -0.0471 & -0.0310 & 0.7212 & . \\
0.0072 & -0.3287 & 0.0006 & -0.0313 & -0.0472 & 0.3322 & 0.4424
\end{array}\right) .
$$

The $R R$ for a woman who is an OC user that smokes $\geq 25$ cigarettes per day would be determined by substituting in the values of the coefficients and applying a unit of 1.0 to each in (8), we get

$$
\begin{aligned}
R R & =\exp (1.2756 \times(1+2.0828) \times(1+0.3392) \times 1) \\
& =\exp (3.6976) \\
& =40.35
\end{aligned}
$$

If we now substitute into (12) the variances and covariances for the three variables in (18), we obtain $V$ as

$$
\begin{aligned}
V & =0.3345(1-0)^{2}+0.0489(1-0)^{2}+0.4424(1-0)^{2}+2(0.0332)+2(-0.3287)+2(-0.0472) \\
& =0.1404
\end{aligned}
$$

The $95 \%$ CI for the $R R$ is then calculated from (9) as

$$
\begin{aligned}
95 \% C I R R & =\exp \left(\ln (R R) \pm Z_{\alpha} \sqrt{V}\right) \\
& =\exp (3.6976 \pm 1.96 \sqrt{0.1404}) \\
& =(19.4,84.1)
\end{aligned}
$$

Now that the $R R$ and Taylor series-based CI have been estimated, we can conduct a simultaneous test of hypothesis for no significant effect due to OC use, smoking $\geq 25$ cigarettes per day with respect to the RR:

$$
\mathrm{H}_{o}: b_{1}=b_{4}=b_{6}=0 \text {. }
$$


For the three factors, the $\mathbf{C}$ matrix is

$$
\mathbf{C}=\left(\begin{array}{lllllll}
0 & 1 & 0 & 0 & 0 & 0 & 0 \\
0 & 0 & 0 & 0 & 1 & 0 & 0 \\
0 & 0 & 0 & 0 & 0 & 0 & 1
\end{array}\right)
$$

By substituting the appropriate values into (16) and performing the matrix manipulation to obtain $\chi^{2}$ we get

$$
\begin{aligned}
& \mathbf{C b}=\left(\begin{array}{lllllll}
0 & 1 & 0 & 0 & 0 & 0 & 0 \\
0 & 0 & 0 & 0 & 1 & 0 & 0 \\
0 & 0 & 0 & 0 & 0 & 0 & 1
\end{array}\right)\left(\begin{array}{c}
-9.2760 \\
1.2756 \\
0.1517 \\
1.1977 \\
2.0828 \\
-1.1709 \\
0.3392
\end{array}\right) \\
& =\left(\begin{array}{l}
1.2756 \\
2.0828 \\
0.3392
\end{array}\right) \\
& \mathbf{b}^{\mathbf{T}} \mathbf{C}^{\mathbf{T}}=\left(\begin{array}{llllllll}
-9.2760 & 1.2756 & 0.1517 & 1.1977 & 2.0828 & -1.1709 & 0.3392
\end{array}\right)\left(\begin{array}{ccc}
0 & 0 & 0 \\
1 & 0 & 0 \\
0 & 0 & 0 \\
0 & 0 & 0 \\
0 & 1 & 0 \\
0 & 0 & 0 \\
0 & 0 & 1
\end{array}\right), \\
& =\left(\begin{array}{lll}
1.2756 & 2.0828 & 0.3392
\end{array}\right), \\
& \mathbf{C V}_{\mathbf{b}}=\left(\begin{array}{lllllll}
0 & 1 & 0 & 0 & 0 & 0 & 0 \\
0 & 0 & 0 & 0 & 1 & 0 & 0 \\
0 & 0 & 0 & 0 & 0 & 0 & 1
\end{array}\right)\left(\begin{array}{cccccccc}
0.4045 & . & . & . & . & . & . \\
-0.0676 & 0.3345 & . & . & . & . & . \\
-0.0087 & 0.0008 & 0.0002 & . & . & . & . \\
-0.0387 & 0.0324 & 0.0002 & 0.0476 & . & . & . \\
-0.0470 & 0.0332 & 0.0004 & 0.0321 & 0.0489 & . & . \\
0.0140 & -0.3294 & 0.0004 & -0.0471 & -0.0310 & 0.7212 & . \\
0.0072 & -0.3287 & 0.0006 & -0.0313 & -0.0472 & 0.3322 & 0.4424
\end{array}\right), \\
& =\left(\begin{array}{ccccccc}
-0.0676 & 0.3345 & 0.0008 & 0.0324 & 0.0332 & -0.3294 & -0.3287 \\
-0.0470 & 0.0332 & 0.0004 & 0.0321 & 0.0489 & -0.0310 & -0.0472 \\
0.0072 & -0.3287 & 0.0006 & -0.0313 & -0.0472 & 0.3322 & 0.4424
\end{array}\right) \text {, } \\
& \mathbf{C V}_{\mathbf{b}} \mathbf{C}^{\mathbf{T}}=\left(\begin{array}{ccccccc}
-0.0676 & 0.3345 & 0.0008 & 0.0324 & 0.0332 & -0.3294 & -0.3287 \\
-0.0470 & 0.0332 & 0.0004 & 0.0321 & 0.0489 & -0.0310 & -0.0472 \\
0.0072 & -0.3287 & 0.0006 & -0.0313 & -0.0472 & 0.3322 & 0.4424
\end{array}\right)\left(\begin{array}{ccc}
0 & 0 & 0 \\
1 & 0 & 0 \\
0 & 0 & 0 \\
0 & 0 & 0 \\
0 & 1 & 0 \\
0 & 0 & 0 \\
0 & 0 & 1
\end{array}\right) \\
& =\left(\begin{array}{ccc}
0.3345 & 0.0332 & -0.3287 \\
0.0332 & 0.0489 & -0.0472 \\
-0.3287 & -0.0472 & 0.4424
\end{array}\right) \\
& {\left[\mathbf{C V}_{\mathbf{b}} \mathbf{C}^{\mathbf{T}}\right]^{-1}=\left(\begin{array}{ccc}
11.0866 & 0.4724 & 8.2877 \\
0.4724 & 22.8178 & 2.7855 \\
8.2877 & 2.7855 & 8.7153
\end{array}\right)}
\end{aligned}
$$




$$
\begin{gathered}
\mathbf{b}^{\mathbf{T}} \mathbf{C}^{\mathbf{T}}\left[\mathbf{C V}_{\mathbf{b}} \mathbf{C}^{\mathbf{T}}\right]^{-1}=\left(\begin{array}{lll}
1.2756 & 2.0828 & 0.3392
\end{array}\right)\left(\begin{array}{ccc}
11.0866 & 0.4724 & 8.2877 \\
0.4724 & 22.8178 & 2.7855 \\
8.2877 & 2.7855 & 8.7153
\end{array}\right), \\
=\left(\begin{array}{lll}
17.9373 & 49.0723 & 19.3296
\end{array}\right) \\
\mathbf{b}^{\mathbf{T}} \mathbf{C}^{\mathbf{T}}\left[\mathbf{C V}_{\mathbf{b}} \mathbf{C}^{\mathbf{T}}\right]^{-1} \mathbf{C b}=\left(\begin{array}{lll}
17.9373 & 49.0723 & 19.3296
\end{array}\right)\left(\begin{array}{l}
1.2756 \\
2.0828 \\
0.3392
\end{array}\right)=131.6453 .
\end{gathered}
$$

The resulting $\chi^{2}$ test statistic of 131.65 is significantly greater than the tabled $\chi_{(3,0.95)}^{2}$ value of 7.82 , indicating that there is a significant joint effect. Thus we reject the hypothesis (22) that there is no joint effect due to OC use, smoking $\geq 25$ cigarettes per day and the interaction between OC use and smoking $\geq 25$ cigarettes per day.

After performing estimating relative risk or testing hypotheses, the user is asked to continue with processing. If the response is "no," the program is terminated, otherwise the algorithm recycles and queries the user for input data for the next cycle (run).

\subsubsection{Testing Hypotheses for Trends}

This section describes how to use COVAR for conducting tests of hypothesis for trends in coefficients. The example is based on multinomial categorical data related to pathological outcome among 2525 thryoid surgical patients. These particular patients resided near the Semipalatinsk Test Site, Kazakstan, where the former Soviet Union conducted nuclear weapons testing from 1949-89. These data are shown in Table 1, which contains 7 columns for outcome (Goiter, Adenoma, Cancer, Hashimoto's thyroiditis, Riedel's thyroiditis, Dequervain's thyroiditis, and Other).

Our goal is to determine whether there has been an increase in the proportion of thyroid cancers identified at surgery throughout the time periods. In the "Cancer" column of Table 1, one can notice the proportion of cancer out of all other outcomes increases over time. Although inferences can be made by visualizing non-zero effects and increasing trends of proportions, we nevertheless must perform hypothesis tests to discredit the null hypothesis of no effect, no interaction, and no trend.

\begin{tabular}{|c|c|c|c|c|c|c|c|c|}
\hline $\begin{array}{l}\text { Calendar } \\
\text { period }\end{array}$ & $\begin{array}{r}\text { Goiter } \\
\text { (all forms) }\end{array}$ & Adenoma & Cancer & $\begin{array}{r}\text { Hashimoto's } \\
\text { thyroiditis }\end{array}$ & $\begin{array}{r}\text { Riedel's } \\
\text { thyroiditis }\end{array}$ & $\begin{array}{r}\text { de Quervain's } \\
\text { thyroiditis }\end{array}$ & Other & Total \\
\hline I (1966-1971) & $324(83.9)$ & $12(3.1)$ & $5(1.3)$ & $37(9.6)$ & $3(0.8)$ & $3(0.8)$ & $2(0.5)$ & $386(100)$ \\
\hline II (1972-1976) & $212(59.9)$ & $95(26.8)$ & $16(4.5)$ & $25(7.1)$ & $1(0.8)$ & - & $5(1.4)$ & $354(100)$ \\
\hline III (1977-1981) & $229(60.4)$ & $85(22.4)$ & $17(4.5)$ & $36(9.5)$ & $5(1.3)$ & $1(0.3)$ & $6(1.6)$ & $379(100)$ \\
\hline IV (1982-1986) & $276(60.1)$ & $59(12.8)$ & $48(10.5)$ & $69(15.0)$ & $1(0.2)$ & $1(0.2)$ & $5(1.1)$ & $459(100)$ \\
\hline V (1987-1991) & $353(54.6)$ & $68(10.5)$ & $105(16.2)$ & $111(17.2)$ & $4(0.6)$ & $2(0.3)$ & $3(0.5)$ & $647(100)$ \\
\hline VI (1992-1994) & $201(67.0)$ & $29(9.7)$ & $29(9.7)$ & $34(11.3)$ & $2(0.6)$ & $2(0.7)$ & $3(1.0)$ & $300(100)$ \\
\hline
\end{tabular}

Table 1: Frequency distribution of 2525 thyroid abnormalities among surgical patients in the Semipalatinsk Region of Kazakstan, number (\%).

First, we made a GSK regression by regressing the ratio of the count for each outcome (column) in each time period by the total row count for each time period. As an example, the first record in the data file for the GSK regression has $324 / 386$ as the dependent variable, followed by $12 / 386$ in the second record, $5 / 386$ in the third record, $37 / 386$ if the fourth, $3 / 386$ in the fifth record, $3 / 386$ in the sixth, and $2 / 386$ in the seventh. The eighth record begins with $212 / 354$ as the dependent variable, and so on. Dummy coding with 0 and 1 was used 
to specify the level of the outcome, time period, and interaction between cancer and time period. Arranged in matrix notation, the column vector of coefficients is

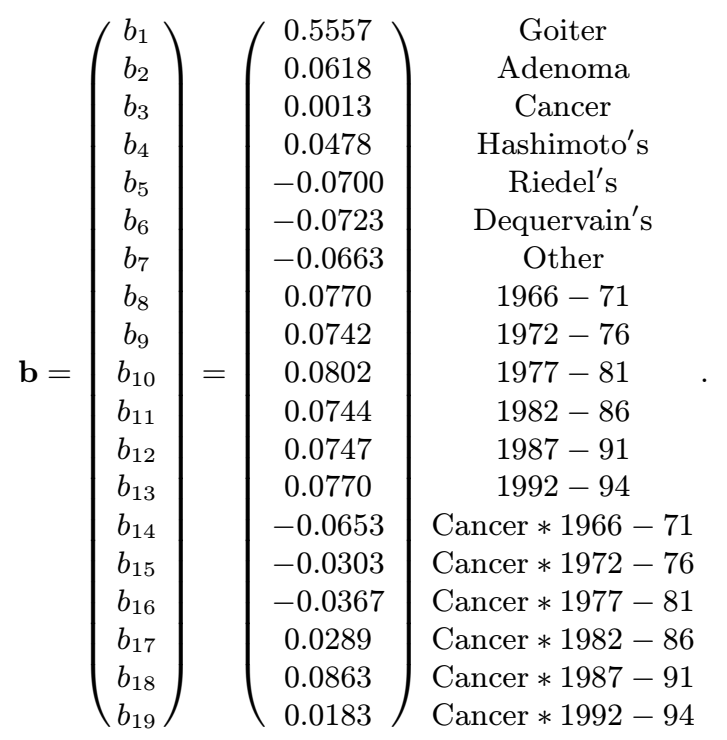

In the parameter vector, we can see coefficients for 7 outcomes (Goiter, Adenoma, Cancer, Hashimoto's thyroiditis, Riedel's thyroiditis, Dequervain's thyroiditis, and Other), 6 time periods (1966-71, 1972-76, 1977-81, 1982-86, 1987-91, and 1992-94), and 6 interaction terms for Cancer and Period (Cancer * 1966-71, Cancer * 197276, Cancer $* 1977-81$, Cancer $* 1982-86$, Cancer $* 1987-91$, Cancer $* 1992-94)$. Using sum-to-zero constraints, we have a total of 19 coefficients. (Sum-to-zero constraints do not use of a constant term nor $p-1$ levels to describe each factor. Rather, $p$ terms are used for each factor without a constant). We notice that coefficients for the outcomes (coefficients 1-7), periods (coefficients 8-13), and cancer*period interaction (coefficients 14-19) are non-zero. The increasing proportion of cancer over time is also noticeable by the increasing trend in values of coefficients 14 through 18, but the trend did not continue for the last time period (coefficient 19).

For the purpose of this example, we shall focus on three hypothesis tests. First, we would like to know if there was a "period effect" present in the data, that is, if the apportionment of various thyroid outcomes changed over time. In (31) the period effect is expressed by the 6 coefficients 8-13. Thus, we are conducting a simultaneous test of the 6 coefficients with the hypothesis

$$
\mathrm{H}_{o}: b_{8}=b_{9}=b_{10}=b_{11}=b_{12}=b_{13}=0 .
$$

Since there are 6 coefficients to test and 19 total coefficients, this results in a $6 \times 19 \mathbf{C}$ matrix shown as

$$
\mathbf{C}=\left(\begin{array}{lllllllllllllllllll}
0 & 0 & 0 & 0 & 0 & 0 & 0 & 1 & 0 & 0 & 0 & 0 & 0 & 0 & 0 & 0 & 0 & 0 & 0 \\
0 & 0 & 0 & 0 & 0 & 0 & 0 & 0 & 1 & 0 & 0 & 0 & 0 & 0 & 0 & 0 & 0 & 0 & 0 \\
0 & 0 & 0 & 0 & 0 & 0 & 0 & 0 & 0 & 1 & 0 & 0 & 0 & 0 & 0 & 0 & 0 & 0 & 0 \\
0 & 0 & 0 & 0 & 0 & 0 & 0 & 0 & 0 & 0 & 1 & 0 & 0 & 0 & 0 & 0 & 0 & 0 & 0 \\
0 & 0 & 0 & 0 & 0 & 0 & 0 & 0 & 0 & 0 & 0 & 1 & 0 & 0 & 0 & 0 & 0 & 0 & 0 \\
0 & 0 & 0 & 0 & 0 & 0 & 0 & 0 & 0 & 0 & 0 & 0 & 1 & 0 & 0 & 0 & 0 & 0 & 0
\end{array}\right) .
$$

The second test we will perform identifies whether the cancer*period interaction is significant. The interaction terms are coefficients $14-19$, so the test notation is

$$
\mathrm{H}_{o}: b_{14}=b_{15}=b_{16}=b_{17}=b_{18}=b_{19}=0 .
$$

The $\mathbf{C}$ matrix now becomes

$$
\mathbf{C}=\left(\begin{array}{lllllllllllllllllll}
0 & 0 & 0 & 0 & 0 & 0 & 0 & 0 & 0 & 0 & 0 & 0 & 0 & 1 & 0 & 0 & 0 & 0 & 0 \\
0 & 0 & 0 & 0 & 0 & 0 & 0 & 0 & 0 & 0 & 0 & 0 & 0 & 0 & 1 & 0 & 0 & 0 & 0 \\
0 & 0 & 0 & 0 & 0 & 0 & 0 & 0 & 0 & 0 & 0 & 0 & 0 & 0 & 0 & 1 & 0 & 0 & 0 \\
0 & 0 & 0 & 0 & 0 & 0 & 0 & 0 & 0 & 0 & 0 & 0 & 0 & 0 & 0 & 0 & 1 & 0 & 0 \\
0 & 0 & 0 & 0 & 0 & 0 & 0 & 0 & 0 & 0 & 0 & 0 & 0 & 0 & 0 & 0 & 0 & 1 & 0 \\
0 & 0 & 0 & 0 & 0 & 0 & 0 & 0 & 0 & 0 & 0 & 0 & 0 & 0 & 0 & 0 & 0 & 0 & 1
\end{array}\right) .
$$


Table 2: Format specification for input disk-file (filename specified by user at run-time).

\begin{tabular}{llrr} 
Description & Form & Columns & Number of Records \\
\hline \multirow{2}{*}{ Number of parameters } & Integer & $1-2$ & 1 \\
Variable names & Character & $1-20$ & $p$ \\
Regression coefficients & Real & $1-16$ & $p$ \\
Variance-covariance matrix & Real & $p(1-16)$ & $p$ \\
& & & \\
\hline
\end{tabular}

Our last test determines the presence of a statistically significant trend in the cancer*period interaction term. Trend tests using contrast matrices are performed by using equal "spacing" throughout the coefficients to be tested. Thus, we have the following notation

$$
\mathrm{H}_{o}:-3 b_{14}-2 b_{15}-b_{16}+b_{17}+2 b_{18}+3 b_{19}=0
$$

and the $\mathbf{C}$ matrix

$$
\mathbf{C}=\left(\begin{array}{lllllllllllllllllll}
0 & 0 & 0 & 0 & 0 & 0 & 0 & 1 & 0 & 0 & 0 & 0 & 0 & -3 & -2 & -1 & 1 & 2 & 3
\end{array}\right) .
$$

Results of the $\chi^{2}$ tests using (16) and $\mathbf{C}$ matrices above are 4575.67 (6 d.f.) for the period effect, 164.99 (6 d.f) for the cancer*period interaction and 64.18 (1 d.f.) for the test of trend for the cancer*period interaction. These results indicate that there is a significant period effect, a significant cancer*period interaction, and a significant trend for the proportion of cancer to increase over time.

\subsection{INPUT}

There are seven forms of input into the computer program: the number of parameters, the variable names of the regression coefficients, the regression coefficients, the variance-covariance matrix of the regression coefficients, the number of coefficients used in RR or tests of hypotheses, the probability of the CIs, and the units applied to each coefficient. The first four items, i.e., the number of parameters, variable names, regression coefficients, and variance-covariance matrix can be entered from either the keyboard or a disk-file. The last three items, namely, the number of coefficients used in RR or tests of hypotheses, probability of the CIs, and units applied to each coefficient can only be entered by using the keyboard.

\section{USER INPUT DATA FILE}

This section discusses the data format when the user has specified that the regression coefficients and variancecovariance matrix are to be entered using the input disk-file. Table 2 lists the data in each record (card) of the input disk-file. When entering the regression coefficients and variance-covariance matrix with the keyboard, however, the data must follow the form described below.

The examples in the Appendix give listings of input files according to the format specified in Table 2.

\section{SAMPLE INPUT/OUPUT CASES}

The output for all computer runs is in tabular form, giving the variable names, the coefficients, variance-covariance matrix, single or joint effects, contrast matrices, units, point estimates and lower and upper bounds of the 1- $\alpha$ CIs for each run, the chi-square test statistic with degrees of freedom and p-values. Two examples using an input disk-file are given in the Appendix. 
Table 3: Names and descriptions of each COVAR file.

\begin{tabular}{lll} 
Filename & Description & Format \\
\hline & & \\
INFILE (optional) & Input file & ASCII text \\
OUTFILE* $_{\text {COVAR.FOR }}$ & Foutput file & ASCII text \\
COVAR.EXE & Executable file & ASCII text \\
& & FORTRAN
\end{tabular}

* Input (optional) and output filenames are specified by the user at run-time.

\section{FILENAMES}

Table 3 lists the names of the files that were used to program, link and execute COVAR. As one notices, the source code is an ASCII text file and the object and executable files have been compiled with Microsoft FORTRAN Powerstation Version 4.10. There is only one optional input data file, which is read when the uses specifies data input from disk. In this case, the filename to be read is specified by the user at run-time.

\section{AVAILABILITY}

The program and all of its subroutines are available from the Journal of Statistical Software free of charge at http://www.stat.ucla.edu/journals/jss/

\section{ACKNOWLEDGEMENTS}

The author gratefully acknowledges Drs. Barry Davis, Ronald Forthofer and Wenyaw Chan of the University of Texas for their review and helpful commentary. Work on this algorithm was partially performed under NASA contract NAS-9 18236.

\section{References}

[1] Forthofer, R.N. and Koch, G.G. (1974). A program for the analysis of compounded functions of categorical data. Comp. Prog. Biomed. 3:237-248.

[2] Cox, D.R. (1972) Regression Models and Life Tables. J. Royal Stat. Soc., Series B. 34:187-220.

[3] Engelman, L. (1991) Stepwise Logistic Regression, PLR Module. BMDP Statistical Software Manual. Berkeley: U. of California.

[4] Frome, E. L. (1981) PREG: A computer program for Poisson regression analysis. Oak Ridge Associated Universities (ORAU). ORAU Publication 178. Oak Ridge: ORAU.

[5] Preston, D.L. and Pierce, D.A. (1989). AMFIT: A program for parameter estimation in additive and multiplicative rate models with grouped survival data - methods, models, and examples. AMFIT User's Guide. Hirosoft International Corporation. Seattle: Hirosoft.

[6] Abramowitz, M. and Stegun, A. (1965) Handbook of Mathematical Functions. New York: Dover.

[7] Grizzle, J.E., Starmer, C.F., Koch, G.G. (1969) Analysis of categorical data for linear models. Biometrics. 25:489-504.

[8] Heiberger, R. (1989) Computation for the analysis of designed experiments. New York: Wiley.

[9] Press, W.H., Flannery, B.P., Teukolsky, S.A., Vetterling, W.T. (1989) Numerical Recipes: The Art of Scientific Computing. New York: Cambridge University Press. 
[10] Schlesselman, J.J. (1982) Case-Control Studies: Design, Conduct, Analysis. Oxford: Oxford University.

[11] Kalbfleisch, J.D., Prentice, R.L. (1980) The Statistical Analysis of Failure Time Data. New York: Wiley.

[12] Hosmer, D.W., Lemeshow, S. (1989) Applied Logistic Regression. New York: Wiley. 


\section{APPENDIX: SAMPLE INPUT/OUTPUT CASES}

Example 1: Data from logistic regression analysis. Odds-ratios and 95

Contents of the input file, EXAMPLE1.DAT, provided in the distribution are listed below:

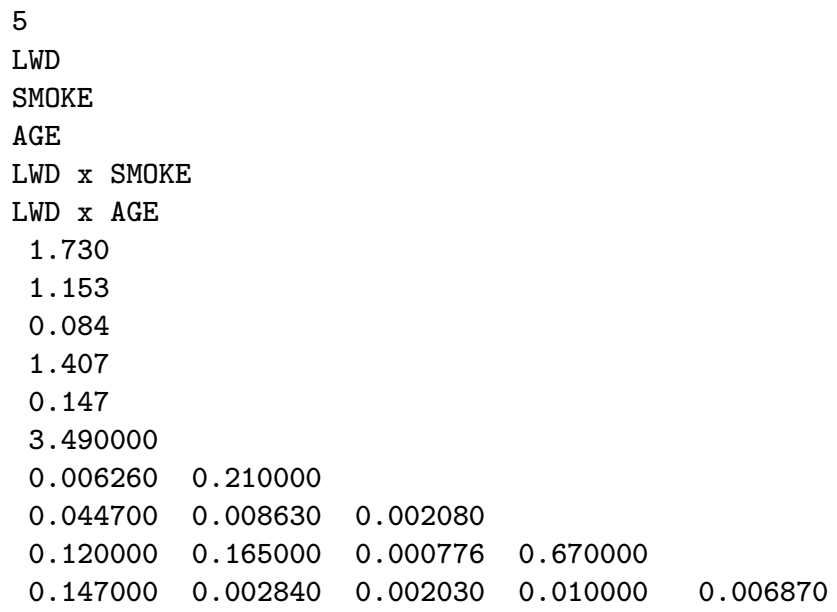

Keyboard specifications at run-time for Example 1.

INPUT FROM KEYBOARD OR FILE (K/F)? F
$1-80.0$
$2-90.0$
$3-95.0$
$4-97.5$
$5-99.0$
6 - OTHER

SELECT PERCENTAGE FOR CONFIDENCE INTERVALS: 2

ENTER NUMBER OF ROWS IN CONTRAST MATRIX: 2

SPECIFY TEST FOR ROW \#1: 1-RR 2-EFFECT 3-TREND: 1

ENTER THE COEFFICIENT INDEX FOR ROW \# 1: 1

ENTER UNIT FOR EFFECT \#1:

1

SPECIFY TEST FOR ROW \#2: 1-RR 2-EFFECT 3-TREND: 1

ENTER THE COEFFICIENT INDEX FOR ROW \# 1: 5

ENTER UNIT FOR EFFECT \#2:

30

$\operatorname{CONTINUE}(\mathrm{Y} / \mathrm{N}) ? \quad \mathrm{Y}$

$1-80.0$

$2-90.0$

$3-95.0$

$4-97.5$

$5-99.0$

6 - OTHER

SELECT PERCENTAGE FOR CONFIDENCE INTERVALS: 2 ENTER NUMBER OF ROWS IN CONTRAST MATRIX: 3

SPECIFY TEST FOR ROW \#1: 1-RR 2-EFFECT 3-TREND: 1 
ENTER THE COEFFICIENT INDEX FOR ROW \# 1: 1 ENTER UNIT FOR EFFECT \#1:

1

SPECIFY TEST FOR ROW \#2: 1-RR 2-EFFECT 3-TREND: 1 ENTER THE COEFFICIENT INDEX FOR ROW \# 1: 4 ENTER UNIT FOR EFFECT \#2:

1

SPECIFY TEST FOR ROW \#3: 1-RR 2-EFFECT 3-TREND: 1 ENTER THE COEFFICIENT INDEX FOR ROW \# 1: 5 ENTER UNIT FOR EFFECT \#3:

30

$\operatorname{CONTINUE}(\mathrm{Y} / \mathrm{N}) ? \quad \mathrm{Y}$

$1-80.0$
$2-90.0$
$3-95.0$
$4-97.5$
$5-99.0$
$6-$ OTHER

SELECT PERCENTAGE FOR CONFIDENCE INTERVALS: 2 ENTER NUMBER OF ROWS IN CONTRAST MATRIX: 1 SPECIFY TEST FOR ROW \#1: 1-RR 2-EFFECT 3-TREND: 1 ENTER THE COEFFICIENT INDEX FOR ROW \# 1: 2 ENTER UNIT FOR EFFECT \#1:

1

$\operatorname{CONTINUE}(\mathrm{Y} / \mathrm{N}) ? \quad \mathrm{Y}$

$1-80.0$

$2-90.0$

$3-95.0$

$4-97.5$

$5-99.0$

6 - OTHER

SELECT PERCENTAGE FOR CONFIDENCE INTERVALS: 2

ENTER NUMBER OF ROWS IN CONTRAST MATRIX: 2

SPECIFY TEST FOR ROW \#1: 1-RR 2-EFFECT 3-TREND: 1 ENTER THE COEFFICIENT INDEX FOR ROW \# 1: 2 ENTER UNIT FOR EFFECT \#1:

1

SPECIFY TEST FOR ROW \#2: 1-RR 2-EFFECT 3-TREND: 1 ENTER THE COEFFICIENT INDEX FOR ROW \# 1: 4 ENTER UNIT FOR EFFECT \#2:

1 $\operatorname{CONTINUE}(\mathrm{Y} / \mathrm{N}) ? \quad \mathrm{Y}$
$1-80.0$
$2-90.0$
$3-95.0$
$4-97.5$
$5-99.0$
6 - OTHER 


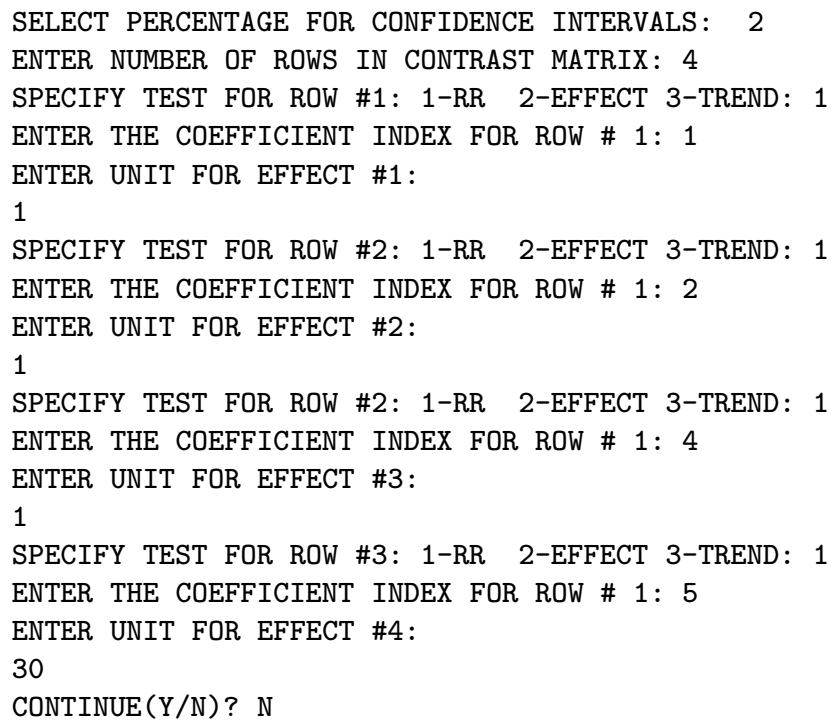

Output file for Example 1. Results are in agreement with those in Table 4.13 of [12].

RUN DATE: 4/10/1997

VARIANCE-COVARIANCE MATRIX OF COEFFICIENTS

\begin{tabular}{|c|c|c|c|c|c|c|}
\hline \multicolumn{2}{|r|}{ B1 } & \multicolumn{2}{|c|}{ B3 } & \multicolumn{2}{|c|}{ B4 } & B5 \\
\hline B1 & 3.4900000 & & & & & \\
\hline B2 & $.62600000 \mathrm{E}-02$ & .21000000 & & & & \\
\hline B3 & $.44700000 \mathrm{E}-01$ & $-.86300000 \mathrm{E}-02$ & & $00 \mathrm{E}-02$ & & \\
\hline B4 & -.12000000 & -.16500000 & .77 & $00 E-03$ & .67000000 & \\
\hline B5 & -.14700000 & $.28400000 \mathrm{E}-02$ & -.20 & $00 E-02$ & $-.10000000 \mathrm{E}-01$ & $.68700000 \mathrm{E}-02$ \\
\hline INDEX & NAME & COEFFI & IENT & STD. E & RROR & \\
\hline $1-$ & LWD & -1.730 & 0000 & 1.8681 & 5400 & \\
\hline $2-$ & SMOKE & 1.153 & 0000 & .4582 & 5760 & \\
\hline $3-$ & AGE & -.084 & 0000 & .0456 & 0702 & \\
\hline 4 & LWD $\mathrm{x}$ SMOKE & -1.407 & 0000 & .8185 & 3530 & \\
\hline 5 & LWD $\times$ AGE & .147 & 0000 & .0828 & 8547 & \\
\hline
\end{tabular}

EFFECTS, CIs AND TEST STATISTICS AT EACH CYCLE

\begin{tabular}{|c|c|c|c|c|c|c|c|c|c|c|c|c|}
\hline CYCLE & B1 & B2 & B3 & B4 & B5 & $\mathrm{CI}$ & $\mathrm{RR}$ & LOWER & UPPER & CHI2 & $\mathrm{DF}$ & PROB \\
\hline 1 & + & - & - & - & + & 95.00 & 14.59 & 2.39 & 89.17 & 8.9594 & 2 & .0113 \\
\hline 2 & + & - & - & + & + & 95.00 & 3.57 & .71 & 18.05 & 9.0557 & 3 & .0286 \\
\hline 3 & - & + & - & - & - & 95.00 & 3.17 & 1.29 & 7.78 & 6.3305 & 1 & .0119 \\
\hline 4 & - & + & - & + & - & 95.00 & .78 & .18 & 3.32 & 6.7952 & 2 & .0335 \\
\hline 5 & + & + & - & + & + & 95.00 & 11.31 & 2.08 & 61.51 & 13.5448 & 4 & .0089 \\
\hline
\end{tabular}




$\begin{array}{rrrrrr}\text { CYCLE } & \text { U1 } & \text { U2 } & \text { U3 } & \text { U4 } & \text { U5 } \\ & & & & & \\ 1 & 1.0 & .0 & .0 & .0 & 30.0 \\ 2 & 1.0 & .0 & .0 & 1.0 & 30.0 \\ 3 & .0 & 1.0 & .0 & .0 & .0 \\ 4 & .0 & 1.0 & .0 & 1.0 & .0 \\ 5 & 1.0 & 1.0 & .0 & 1.0 & 30.0\end{array}$

Example 2: Data from multinomial categorical regression of data for thyroid pathologies among 2525 surgical patients who lived near the Semipalatinsk Test Site, Kazakstan, where nuclear weaopns were tested from 194989. Test of hypotheses for effects of time period, cancer and time period interaction, and trend for increasing cancer over time periods. Regression coefficients obained from use of a Grizzle-Starmer-Koch additive model for multinomially distributed data. All data stored in input data file EXAMPLE2.DAT.

Contents of input file EXAMPLE2.DAT provided in distribution are shown below:

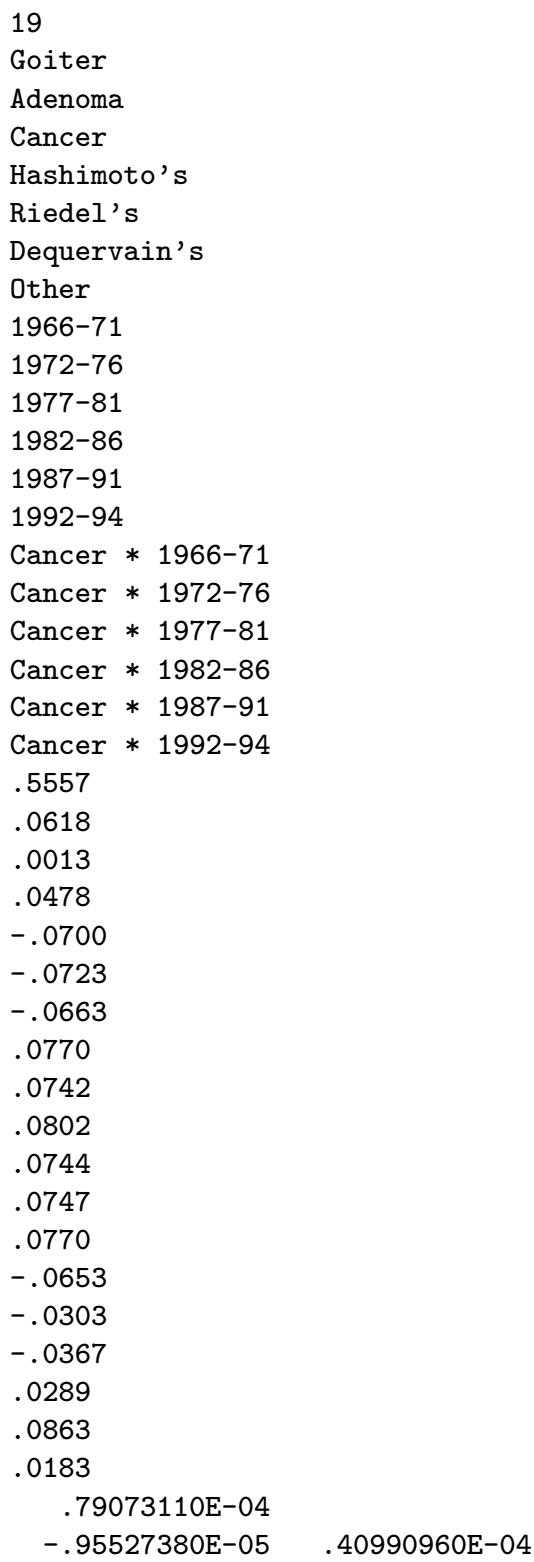




$$
\begin{array}{rr}
-.66085770 \mathrm{E}-05 & -.36034480 \mathrm{E}-05 \\
-.92355610 \mathrm{E}-05 & -.57279850 \mathrm{E}-05 \\
-.60641810 \mathrm{E}-05 & -.25531110 \mathrm{E}-05 \\
-.59866910 \mathrm{E}-05 & -.24739670 \mathrm{E}-05 \\
-.61796430 \mathrm{E}-05 & -.26697410 \mathrm{E}-05 \\
.58893280 \mathrm{E}-05 & .23836660 \mathrm{E}-05 \\
.59764610 \mathrm{E}-05 & .24589970 \mathrm{E}-05 \\
.58217260 \mathrm{E}-05 & .23477210 \mathrm{E}-05 \\
.59077310 \mathrm{E}-05 & .23905490 \mathrm{E}-05 \\
.58233450 \mathrm{E}-05 & .23068350 \mathrm{E}-05 \\
.60272670 \mathrm{E}-05 & .25221220 \mathrm{E}-05 \\
.35120810 \mathrm{E}-06 & .85173070 \mathrm{E}-06 \\
-.72239960 \mathrm{E}-06 & -.21007690 \mathrm{E}-06 \\
-.46918090 \mathrm{E}-06 & -.32303120 \mathrm{E}-09 \\
-.15658960 \mathrm{E}-05 & -.10538430 \mathrm{E}-05 \\
-.15494840 \mathrm{E}-05 & -.10381020 \mathrm{E}-05 \\
-.26528570 \mathrm{E}-05 & -.21528250 \mathrm{E}-05
\end{array}
$$$$
-.60641810 \mathrm{E}-05 \quad-.25531110 \mathrm{E}-05 \quad-.63490720 \mathrm{E}-06
$$$$
-.59866910 \mathrm{E}-05 \quad-.24739670 \mathrm{E}-05-.57919900 \mathrm{E}-06
$$

Keyboard specifications at run-time for Example 2.

$$
\begin{array}{rrr}
.37546310 \mathrm{E}-04 & & \\
-.22354460 \mathrm{E}-05 & .31471900 \mathrm{E}-05 & \\
-.21561200 \mathrm{E}-05 & .11089230 \mathrm{E}-05 & . \\
-.23522160 \mathrm{E}-05 & .86166600 \mathrm{E}-06 & . \\
.20666520 \mathrm{E}-05 & -.10018460 \mathrm{E}-05 & . \\
.21406180 \mathrm{E}-05 & -.12317640 \mathrm{E}-05 & . \\
.20342310 \mathrm{E}-05 & -.66307480 \mathrm{E}-06 & . \\
.20721830 \mathrm{E}-05 & -.12833040 \mathrm{E}-05 & . \\
.19885520 \mathrm{E}-05 & -.13350450 \mathrm{E}-05 & . \\
.22051640 \mathrm{E}-05 & -.85483440 \mathrm{E}-06 & . \\
.89697650 \mathrm{E}-06 & .12687060 \mathrm{E}-05 & . \\
-.16347970 \mathrm{E}-06 & .51214890 \mathrm{E}-06 & . \\
.41403640 \mathrm{E}-07 & .41954150 \mathrm{E}-07 & . \\
-.10072680 \mathrm{E}-05 & -.34852620 \mathrm{E}-06 & . \\
-.99160810 \mathrm{E}-06 & -.36476370 \mathrm{E}-06 & . \\
-.21076640 \mathrm{E}-05 & -.17444170 \mathrm{E}-05 & .
\end{array}
$$

INPUT FROM KEYBOARD OR FILE (K/F)? F

$$
\begin{aligned}
& 1-80.0 \\
& 2-90.0 \\
& 3-95.0 \\
& 4-97.5 \\
& 5-99.0 \\
& 6-\text { OTHER }
\end{aligned}
$$

SELECT PERCENTAGE FOR CONFIDENCE INTERVALS: 2 ENTER NUMBER OF ROWS IN CONTRAST MATRIX: 6 SPECIFY TEST FOR ROW \#1: 1-RR 2-EFFECT 3-TREND: 2 ENTER THE COEFFICIENT INDEX FOR ROW \# 1: 8 SPECIFY TEST FOR ROW \#1: 1-RR 2-EFFECT 3-TREND: 2 ENTER THE COEFFICIENT INDEX FOR ROW \# 2: 9 SPECIFY TEST FOR ROW \#1: 1-RR 2-EFFECT 3-TREND: 2 ENTER THE COEFFICIENT INDEX FOR ROW \# 3: 10 SPECIFY TEST FOR ROW \#1: 1-RR 2-EFFECT 3-TREND: 2 ENTER THE COEFFICIENT INDEX FOR ROW \# 4: 11 SPECIFY TEST FOR ROW \#1: 1-RR 2-EFFECT 3-TREND: 2 ENTER THE COEFFICIENT INDEX FOR ROW \# 5: 12 SPECIFY TEST FOR ROW \#1: 1-RR 2-EFFECT 3-TREND: 2 ENTER THE COEFFICIENT INDEX FOR ROW \# 6: 13 $\operatorname{CONTINUE}(\mathrm{Y} / \mathrm{N})$ ? Y

$$
\begin{aligned}
& 1-80.0 \\
& 2-90.0 \\
& 3-95.0 \\
& 4-97.5 \\
& 5-99.0 \\
& 6-\text { OTHER }
\end{aligned}
$$

SELECT PERCENTAGE FOR CONFIDENCE INTERVALS: 2 ENTER NUMBER OF ROWS IN CONTRAST MATRIX: 6 
ENTER THE COEFFICIENT INDEX FOR ROW \# 1: 14 SPECIFY TEST FOR ROW \#1: 1-RR 2-EFFECT 3-TREND: 2 ENTER THE COEFFICIENT INDEX FOR ROW \# 2: 15 SPECIFY TEST FOR ROW \#1: 1-RR 2-EFFECT 3-TREND: 2 ENTER THE COEFFICIENT INDEX FOR ROW \# 3: 16 SPECIFY TEST FOR ROW \#1: 1-RR 2-EFFECT 3-TREND: 2 ENTER THE COEFFICIENT INDEX FOR ROW \# 4: 17 SPECIFY TEST FOR ROW \#1: 1-RR 2-EFFECT 3-TREND: 2 ENTER THE COEFFICIENT INDEX FOR ROW \# 5: 18 SPECIFY TEST FOR ROW \#1: 1-RR 2-EFFECT 3-TREND: 2 ENTER THE COEFFICIENT INDEX FOR ROW \# 6: 19 $\operatorname{CONTINUE}(\mathrm{Y} / \mathrm{N})$ ? Y
$1-80.0$
$2-90.0$
$3-95.0$
$4-97.5$
$5-99.0$
6 - OTHER

SELECT PERCENTAGE FOR CONFIDENCE INTERVALS: 2 ENTER NUMBER OF ROWS IN CONTRAST MATRIX: 1 SPECIFY TEST FOR ROW \#1: 1-RR 2-EFFECT 3-TREND: 3 ENTER BEGINNING COEFFICIENT INDEX: 14 ENTER ENDING COEFFICIENT INDEX: 19 CONTINUE $(\mathrm{Y} / \mathrm{N})$ ? N

Output file for Example 2.

VARIANCE-COVARIANCE MATRIX OF COEFFICIENTS

\begin{tabular}{|c|c|c|c|c|c|c|}
\hline & B1 & B2 & B3 & B4 & B5 & B6 \\
\hline B1 & $.79073110 \mathrm{E}-04$ & & & & & \\
\hline B2 & $-.95527380 \mathrm{E}-05$ & $.40990960 \mathrm{E}-04$ & & & & \\
\hline B3 & $-.66085770 \mathrm{E}-05$ & $-.36034480 \mathrm{E}-05$ & $.18156760 \mathrm{E}-04$ & & & \\
\hline B4 & $-.92355610 \mathrm{E}-05$ & $-.57279850 \mathrm{E}-05$ & $-.33316720 \mathrm{E}-05$ & $.37546310 \mathrm{E}-04$ & & \\
\hline B5 & $-.60641810 \mathrm{E}-05$ & $-.25531110 \mathrm{E}-05$ & $-.63490720 \mathrm{E}-06$ & $-.22354460 \mathrm{E}-05$ & $.31471900 \mathrm{E}-05$ & \\
\hline B6 & $-.59866910 \mathrm{E}-05$ & $-.24739670 \mathrm{E}-05$ & $-.57919900 \mathrm{E}-06$ & $-.21561200 \mathrm{E}-05$ & $.11089230 \mathrm{E}-05$ & $.23669360 \mathrm{E}-05$ \\
\hline B7 & $-.61796430 \mathrm{E}-05$ & $-.26697410 \mathrm{E}-05$ & $-.72608150 \mathrm{E}-06$ & $-.23522160 \mathrm{E}-05$ & $.86166600 \mathrm{E}-06$ & $.96027090 \mathrm{E}-06$ \\
\hline & B8 & B9 & B10 & B11 & B12 & B13 \\
\hline B8 & $.57360130 \mathrm{E}-05$ & & & & & \\
\hline B9 & $.61598620 \mathrm{E}-06$ & $.39929060 \mathrm{E}-05$ & & & & \\
\hline B10 & $-.20915850 \mathrm{E}-07$ & $.25510090 \mathrm{E}-06$ & $.79012830 \mathrm{E}-05$ & & & \\
\hline B11 & $.65550000 \mathrm{E}-06$ & $.99558190 \mathrm{E}-06$ & $.29706330 \mathrm{E}-06$ & $.35407700 \mathrm{E}-05$ & & \\
\hline B12 & $.69092170 \mathrm{E}-06$ & $.10233200 \mathrm{E}-05$ & $.33625410 \mathrm{E}-06$ & $.10592090 \mathrm{E}-05$ & $.30728940 \mathrm{E}-05$ & \\
\hline B13 & $.16885510 \mathrm{E}-06$ & $.46789670 \mathrm{E}-06$ & $-.16786120 \mathrm{E}-06$ & $.50748810 \mathrm{E}-06$ & $.54302610 \mathrm{E}-06$ & $.70760190 \mathrm{E}-05$ \\
\hline B14 & $-.57919500 \mathrm{E}-05$ & $-.74271730 \mathrm{E}-06$ & $.72774950 \mathrm{E}-07$ & $-.82439780 \mathrm{E}-06$ & $-.90696110 \mathrm{E}-06$ & $-.11778330 \mathrm{E}-06$ \\
\hline & B15 & B16 & B17 & B18 & B19 & \\
\hline B15 & $.10982830 \mathrm{E}-03$ & & & & & \\
\hline B16 & $-.14714190 \mathrm{E}-04$ & $.10707580 \mathrm{E}-03$ & & & & \\
\hline B17 & $-.26892360 \mathrm{E}-04$ & $-.26489030 \mathrm{E}-04$ & $.16784310 \mathrm{E}-03$ & & & \\
\hline
\end{tabular}




$\begin{array}{rrr}\text { INDEX NAME } & \text { COEFFICIENT } & \text { STD. ERROR } \\ 1-\text { Goiter } & .55570000 & .00889231 \\ 2-\text { Adenoma } & .06180000 & .00640242 \\ 3-\text { Cancer } & .00130000 & .00426108 \\ 4-\text { Hashimoto's } & .04780000 & .00612750 \\ 5-\text { Riedel's } & -.07000000 & .00177403 \\ 6-\text { Dequervain's } & -.07230000 & .00153848 \\ 7-\text { Other } & -.06630000 & .00209143 \\ 8-\text { 1966-71 } & .07700000 & .00239500 \\ 9-1972-76 & .07420000 & .00199823 \\ 10-1977-81 & .08020000 & .00281092 \\ 11-1982-86 & .07440000 & .00188169 \\ 12-1987-91 & .07470000 & .00175297 \\ 13-1992-94 & .07700000 & .00266008 \\ 14-\text { Cancer * 1966-71 } & -.06530000 & .00694946 \\ 15-\text { Cancer *1972-76 } & -.03030000 & .01047990 \\ 16-\text { Cancer * 1977-81 } & -.03670000 & .01034774 \\ 17-\text { Cancer * 1982-86 } & .02890000 & .01295543 \\ 18-\text { Cancer * 1987-91 } & .08630000 & .01310799 \\ 19-\text { Cancer * 1992-94 } & .01830000 & .01525951\end{array}$

EFFECTS, CIs AND TEST STATISTICS AT EACH CYCLE

CYCLE B1 B2 B3 B4 B5 B6 B7 B8 B9 B10B11B12B13B14B15B16B17B18B19

1 - EFFECT TEST, CONTRAST MATRIX BELOW CONTRAST MATRIX:

0. 0. 0. 0. 0. 0. 0.1.0.0.0.0.0.0.0.0.0.0.0.0. 0. 0. 0.0 .0 .0 .0 .0 .0 .1 .0 .0 .0 .0 .0 .0 .0 .0 .0 .0$. 0. 0. 0. 0. 0. 0. 0. 0. 0. 1. 0. 0.0.0.0.0.0.0.0.0.

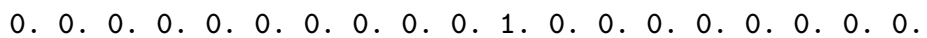
0. 0.0 .0 .0 .0 .0 .0 .0 .0 .0 .1 .0 .0 .0 .0 .0 .0 .0$. 0. 0. 0. 0. 0. 0. 0.0.0.0.0.0.1.0.0.0.0.0.0. 0.

2 - EFFECT TEST, CONTRAST MATRIX BELOW CONTRAST MATRIX:

0. 0. 0. 0. 0. 0. 0. 0. 0.0.0.0.0.1.0.0.0.0.0.0. 0. 0. 0.0 .0 .0 .0 .0 .0 .0 .0 .0 .0 .0 .0 .1 .0 .0 .0 .0$. 0. 0.0 .0 .0 .0 .0 .0 .0 .0 .0 .0 .0 .0 .0 .1 .0 .0 .0$. 0. 0.0 .0 .0 .0 .0 .0 .0 .0 .0 .0 .0 .0 .0 .0 .1 .0 .0$.

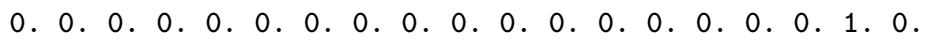
0. 0. 0. 0. 0. 0. 0. 0. 0. 0. 0. 0. 0. 0. 0. 0. 0. 0.1 .

3 - TREND TEST, SEE CONTRAST MATRIX BELOW CONTRAST MATRIX:

0. 0. 0. 0. 0. 0. 0. 0. 0. 0. 0.0.0.-3.-2.-1.1.2. 3 .

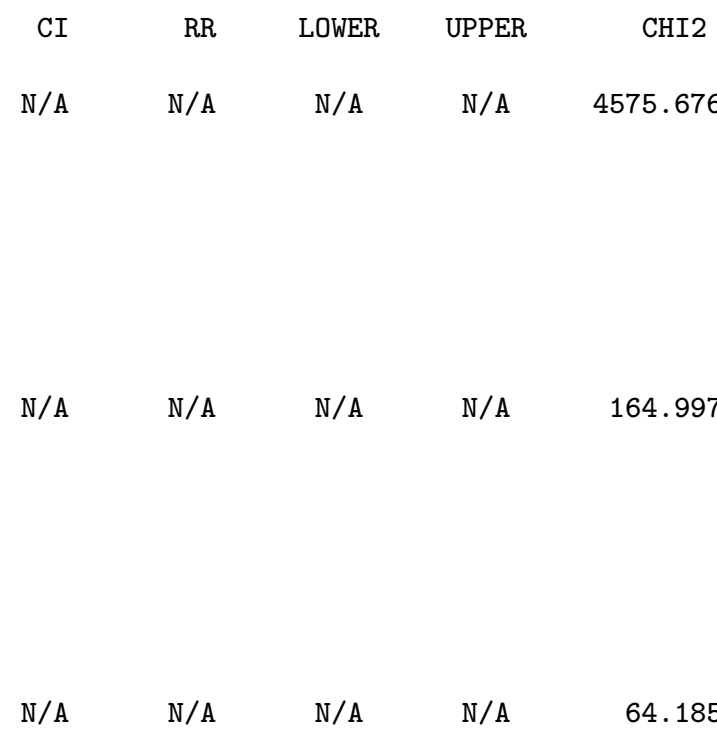


UNITS APPLIED TO COEFFICENTS AT EACH CYCLE

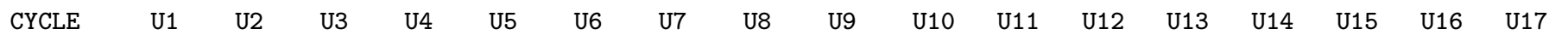

